\section{HUBUNGAN PENYAKIT GIGI DAN MULUT DENGAN KUALITAS HIDUP ANAK DI KECAMATAN TALAWAAN KABUPATEN MINAHASA UTARA}

Diterima 30 Juli 2017

Disetujui 27 Oktober 2017

Dipublikasikan 1 September 2017
JKMA

Jurnal Kesehatan Masyarakat Andalas diterbitkan oleh:

Program Studi S-1 Kesehatan Masyarakat Fakultas Kesehatan Masyarakat Universitas Andalas

p-ISSN 1978-3833

e-ISSN 2442-6725

11(2)115-119

@2017 JKMA

http://jurnal.fkm.unand.ac.id/index.php/jkma/

Youla Karamoy $^{1 凶}$, Anneke Tahulending $^{1}$, Ni Made Yuliana ${ }^{1}$

${ }^{1} J u r u s a n$ Keperawatan Gigi, Politeknik Kesehatan Kemenkes, Manado, Sulawesi Utara 95163

\begin{abstract}
Abstrak
Kesehatan gigi dan mulut memegang peranan penting dalam hidup seseorang untuk mendapatkan kesehatan umum yang baik. Penyakit mulut dapat menyebabkan rasa sakit, penderitaan, hambatan psikologis dan deprivasi sosial, yang sangat merugikan baik individu maupun masyarakat termasuk didalamnya adalah anak-anak. Anak usia sekolah merupakan salah satu kelompok yang rentan terhadap berbagai masalah kesehatan gigi dan mulut. Tujuan penelitian ini untuk mengetahui hubungan penyakit gigi dan mulut dengan kualitas hidup anak. Jenis Penelitian adalah cross-sectional di Kecamatan Talawaan Kabupaten Minahasa Utara. Teknik pengambilan sampel menggunakan convenience sampling. Analisis data secara univariat dan analisis bivariat dengan menggunakan uji korelasi pearson. Hasil univariat diperoleh rata-rata karies gigi dengan indeks PUFA adalah 0,77, sedangkan rata-rata karies gigi dengan Calculus Index (CI) adalah 0,75 . Rata-rata indeks PUFA dari subjek yang orang tuanya bekerja secara non formal lebih tinggi $(0,88)$ dibandingkan dengan subjek yang orang tuanya bekerja secara formal $(0,76)$. Hasil analisis bivariat diperoleh hubungan bermakna antara karies gigi dengan kualitas hidup anak indek PUFA $(r=-0,418, p=0,000)$ dan Calculus Index $(r=-0,158, p=0,091)$. Semakin baik status kesehatan gigi anak maka kualitas hidup anak juga baik. Oleh karena itu disarankan memperhatikan status kesehatan gigi dan mulut anak agar dapat meningkatkan kualitas hidupnya.
\end{abstract}

Kata Kunci: Karang gigi, Karies gigi, Kualitas hidup, Penyakit gigi

\title{
THE RELATIONSHIP OF DENTAL AND MOUTH DISEASE WITH THE QUALITY OF LIFE OF CHILDREN IN TALAWAAN MINAHASA SUB-DISTRICT
}

Abstract

Dental and mouth health play an important role to get good health. Mouth disease cause pain, suffering, social deprivation and psychological barriers, which are highly detrimental to both individuals and society including the children. School age children is one of the groups that are vulnerable to dental and mouth health problems. The study aim to know the relationship of dental and mouth disease with the child's quality of life. The study design was cross-sectional conducted in North Minahasa subdistrict with sample taken by convenience sampling. Data analysis of univariate and bivariat analysis. Results of univariate analysis obtained average dental caries with PUFA index was 0.77 and the Calculus Index (CI) was 0.75 . The average of PUFA index of subjects whose parents work in nonformal higher (0.88) than subjects whose parents work in a formal (0.76). Bivariat analysis obtained significant corelation between dental caries and the child's quality of life index PUFA $(\mathrm{r}=-0.418, \mathrm{p}=0.000)$ and Calculus Index $(\mathrm{r}=-0.158, \mathrm{p}=0,091)$. The better children's dental health status the better the child's quality of life. It is therefore advised to care for dental and mouth health in children so that can increase the quality of life .

Keywords: Dental caries, Dental disease, Quality of life,Tartar

$\nabla$ Korespondensi Penulis:

Jurusan Keperawatan Gigi, Politeknik Kesehatan Kemenkes Jl. R.W. Monginsidi Malalayang II Manado, Sulawesi Utara, 95163

Email : karamoyyoula@gmail.com 


\section{Pendahuluan}

Kesehatan gigi dan mulut memegang peranan penting dalam hidup seseorang untuk mendapatkan kesehatan umum yang baik. Keadaan mulut yang buruk, seperti banyaknya gigi yang berlubang dapat mengganggu fungsi dan aktivitas sistem stomatognatik.Penyakit mulut dapat menyebabkan rasa sakit, penderitaan, hambatan psikologis dan deprivasi sosial, yang sangat merugikan baik individu maupun masyarakat termasuk didalamnya adalah anak-anak. Anak usia sekolah merupakan salah satu kelompok yang rentan terhadap berbagai masalah kesehatan gigi dan mulut. ${ }^{(1)}$

Berdasarkan Riset Kesehatan Dasar (Riskesdas) tahun 2013, ada 24,8 \% anak usia 12 tahun yang mempunyai masalah kesehatan gigi dan mulut. Selain itu, terjadi kecenderungan peningkatan pengalaman karies yang dialami masyarakat. Pengalaman karies pada kelompok umur 12 tahun adalah 0,91 pada tahun 2007 dan meningkat menjadi 1,4 pada temuan tahun 2013. Di Indonesia ada $62,4 \%$ penduduk merasa terganggu dalam pekerjaan ataupun di sekolah karena sakit gigi rata-rata 3,86 hari pertahun. Masalah kesehatan gigi ini dapat mengakibatkan salah satunya adalah murid tersebut tidak hadir di sekolah dan memberikan efek terhadap daya konsentrasi serta prestasi di sekolah. ${ }^{(2)}$

Kualitas hidup seringkali mempunyai makna yang berbeda pada setiap orang karena dipengaruhi oleh banyak faktor seperti keuangan, keamanan, atau kesehatan termasuk didalamnya kesehatan gigi dan mulut.Kualitas hidup mengacu pada kemampuan pasien untuk dapat menikmati aktivitas kehidupan yang normal.Hidup sehat merupakan bagian dari kualitas hidup, karena itu sehat tidak hanya secara fisik saja tetapi juga harus sehat mental dan kehidupan sosialnya. Kesehatan rongga mulut merupakan bagian yang tidak terpisahkan dari kesehatan secara umum, oleh sebab itu, untuk mengukur kesehatan gigi dan mulut harus mempertimbangkan fungsi serta dampak yang ditimbulkan dari kondisi gigi dan mulut terhadap kehidupan sehari-hari. ${ }^{(3)}$

Keadaan gigi dan mulut anak umur 11-12 tahun harus dijaga karena sebagian besar gigi tetap sudah erupsi. Selain itu pada masa ini merupakan masa peralihan dari masa anak-anak ke masa remaja dimana terjadi perkembangan konsep diri mereka yang sangat kompleks dan melibatkan sejumlah aspek dalam diri mereka, sehingga apabila terjadi suatu kelainan atau masalah dalam rongga mulut maka dapat mempengaruhi perkembangan dan pergaulan anak tersebut di lingkungannya serta berpengaruh pada kualitas hidupnya. ${ }^{(3,4)}$

Penelitian ini secara khusus bertujuan untuk mengetahui hubungan penyakit gigi dan mulut anak dengan kualitas hidup anak di Kecamatan Talawaan Kabupaten Minahasa Utara.

\section{Metode}

Jenis penelitian survei analitik dengan cross-sectional study. Penelitian ini dilakukan pada bulan Agustus hingga September tahun 2016 di delapan sekolah dasar negeri yang ada di Kecamatan Talawaan Kabupaten Minahasa Utara Provinsi Sulawesi Utara. Pengambilan sampel secara convenience sampling dengan kriteria anak berumur 11-12 tahun. Jumlah sampel adalah 115 orang. Variabel bebas dalam penelitian ini adalah penyakit gigi dan mulut yang dilihat adalah karies gigi menggunakan indeks PUFA (Pulp, Ulcer, Fistel, Abscess) dan karang gigi menggunakan indeks CI (Calculus Index). ${ }^{(5,6,7)} 6$ Variabel terikat adalah kualitas hidup anak akan dinilai dengan kuesioner COHIP SF-19..$^{(8,9,10)}$ Instrumen yang digunakan adalah diagnosa set (kaca mulut, excavator, sonde, pinset), nierbekken, gelas kumur, masker, sarung tangan, dan format pemeriksaan serta kuesioner COHIP SF-19. Analisa data secara univariat dan bivariat menggunakan analisis statistik uji korelasi pearson..$^{(11)}$

\section{Hasil}

Hasil analisis univariat didapatkan distribusi subjek berdasarkan jenis kelamin yaitu perempuan $49.6 \%$ sedangkan laki-laki $50.4 \%$. Jenis pekerjaan orang tua dikategorikan menjadi dua yaitu formal dan non formal. Jenis pekerjaan yang termasuk kategori formal yaitu PNS dan karyawan swasta, sedangkan yang termasuk kategori non formal yaitu petani, pedagang, buruh, supir, pembantu rumah tangga. Dari dua jenis kate- 
Tabel 1 Distribusi Frekuensi Subjek Berdasarkan Jenis Kelamin Dan Pekerjaan Orang Tua

\begin{tabular}{ccc}
\hline Variabel & n & $\%$ \\
\hline Jenis Kelamin & & \\
Laki-laki & 57 & 49.6 \\
Perempuan & 58 & 50.4 \\
Pekerjaan Orang Tua & & \\
Formal & 39 & 33.9 \\
Non Formal & 76 & 66.1 \\
Jumlah & 115 & 100 \\
\hline
\end{tabular}

gori pekerjaan, orang tua yang bekerja secara non formal lebih banyak (66.1\%) dibandingkan yang bekerja secara formal $(33,9 \%)$. Status karies gigi dari subjek berdasarkan jenis kelamin diketahui bahwa rata-rata indeks PUFA pada subjek perempuan lebih rendah (0.72) dibandingkan pada laki-laki (0.96). Dari total sampel, yang mempunyai karang gigi kategori baik lebih banyak pada subjek perempuan dibandingkan dengan laki-laki. Rata-rata indeks kalkulus pada keseluruhan subjek adalah 0.75 dimana nilai ini termasuk dalam kategori baik. Status karies gigi berdasarkan pekerjaan orang tua diketahui bahwa rata-rata indeks PUFA dari subjek yang orang tuanya bekerja secara non formal lebih tinggi $(0,88)$ dibandingkan dengan subjek yang orang tuanya bekerja secara formal $(0,76)$. Untuk karang gigi, kategori baik lebih banyak pada subjek yang orang tuanya bekerja secara formal dengan CI $(0,69)$ dibandingkan dengan orang tua yang bekerja secara non formal dengan CI $(0,78)$.

Hasil analisis bivariat didapatkan hubungan antara karies gigi yang dinilai dengan indeks PUFA dengan kualitas hidup anak diperoleh p-value sebesar 0,000 (p-value $<0,05$ ) dengan nilai r sebesar -0,418. Hal ini menunjukkan bahwa terdapat hubungan yang bermakna antara kualitas hidup anak dengan karies gigi dengan arah korelasi negatif. Analisis statistik pada variabel karang gigi dengan kualitas hidup anak diperoleh p-value sebesar 0,091 (p-value > 0,05) dengan nilai $\mathrm{r}$ sebasar -0,158. Hal ini menunjukkan bahwa tidak terdapat hubungan yang bermakna antara karang gigi dengan kualitas hidup anak dengan arah korelasi negatif
Tabel 2. Distribusi Frekuensi Karies Gigi Dan Karang Gigi pada Subjek Berdasarkan Jenis Kelamin

\begin{tabular}{|c|c|c|c|c|c|c|}
\hline \multirow[t]{2}{*}{ Variabel } & \multicolumn{2}{|c|}{ Laki-laki } & \multicolumn{2}{|c|}{$\begin{array}{l}\text { Perem- } \\
\text { puan }\end{array}$} & \multicolumn{2}{|c|}{ Total } \\
\hline & $\mathbf{n}$ & $\%$ & $\mathrm{n}$ & $\%$ & $\mathrm{n}$ & $\%$ \\
\hline \multicolumn{7}{|l|}{ Karies Gigi } \\
\hline $\begin{array}{l}\text { Pulp in- } \\
\text { volvement }\end{array}$ & 30 & 52.6 & 28 & 48.3 & 58 & 50.4 \\
\hline Ulcer & 0 & 0 & 0 & 0 & 0 & 0 \\
\hline Fistel & 1 & 1.75 & 0 & 0 & 1 & 0.9 \\
\hline Abses & 6 & 10.5 & 1 & 1.72 & 6 & 5.2 \\
\hline $\begin{array}{l}\text { Rata-rata } \\
\text { PUFA }\end{array}$ & \multicolumn{2}{|c|}{0.96} & \multicolumn{2}{|c|}{0.72} & \multicolumn{2}{|c|}{0.77} \\
\hline \multicolumn{7}{|l|}{$\begin{array}{l}\text { Calculus Index } \\
\text { (CI) }\end{array}$} \\
\hline Baik & 21 & 36.8 & 24 & 41.4 & 45 & 39.1 \\
\hline Sedang & 29 & 50.9 & 26 & 44.8 & 55 & 47.8 \\
\hline Buruk & 7 & 12.3 & 8 & 13.8 & 15 & 13.1 \\
\hline Rata-rata CI & \multicolumn{2}{|c|}{0.77} & \multicolumn{2}{|c|}{0.73} & \multicolumn{2}{|c|}{0.75} \\
\hline
\end{tabular}

\section{Pembahasan}

Dari hasil penelitian ini diperoleh data bahwa sebagian besar subjek (50.4\%) mempunyai karies gigi lanjut yangbelum dirawat. Dimana rata-rata indeks PUFA adalah 0,77 yang artinya bahwa pada setiap anak yang menjadi subjek pada penelitian ini mempunyai sekitar 1 gigi karies yang tidak terawat. Sedangkan untuk karang gigi sebagian besar dalam kategori sedang $(47,8 \%)$ dan baik $(39,1 \%)$, dimana untuk kategori yang buruk, hanya $13,1 \%$. Masih tingginya masalah kesehatan gigi pada anak dapat memberikan dampak negatif terhadap perkembangan anak yang nantinya akan mempengaruhi kualitas hidup dari anak yang bersangkutan.

Pada penelitian ini diketahui bahwa terdapat hubungan yang signifikan antara status karies gigi dengan status kualitas hidup anak dalam hubungan dengan kesehatan gigi dan mulut anak, yang ditunjukkan dengan nilai p-value adalah $0.000<$ 0,05, dengan arah korelasi negative. Hal ini berarti anak yang mempunyai masalah kesehatan gigi yaitu tingginya jumlah karies gigi dan maka seiring dengan hal tersebut, kualitas hidup dari anak tersebut akan menurun atau rendah. Karies gigi dapat menimbulkan rasa sakit, baik pada gigi 
Tabel 3. Distribusi Frekuensi Karies Gigi Dan Karang Gigi Pada Subjek Berdasarkan Jenis Kelamin

\begin{tabular}{|c|c|c|c|c|c|c|}
\hline \multirow[t]{2}{*}{ Variabel } & \multicolumn{2}{|c|}{ Formal } & \multicolumn{2}{|c|}{$\begin{array}{c}\text { Non For- } \\
\text { mal }\end{array}$} & \multicolumn{2}{|c|}{ Total } \\
\hline & $\mathrm{n}$ & $\%$ & $\mathbf{n}$ & $\%$ & $\mathrm{n}$ & $\%$ \\
\hline \multicolumn{7}{|l|}{ Karies Gigi } \\
\hline $\begin{array}{l}\text { Pulp in- } \\
\text { volvement }\end{array}$ & 19 & 48.7 & 39 & 51.3 & 58 & 50.4 \\
\hline Ulcer & 0 & 0 & 0 & 0 & 0 & 0 \\
\hline Fistel & 0 & 0 & 1 & 1.3 & 1 & 0.9 \\
\hline Abses & 3 & 7.7 & 4 & 5.3 & 6 & 5.2 \\
\hline $\begin{array}{l}\text { Rata-rata } \\
\text { PUFA }\end{array}$ & \multicolumn{2}{|c|}{0.76} & \multicolumn{2}{|c|}{0.88} & \multicolumn{2}{|c|}{0.84} \\
\hline \multicolumn{7}{|l|}{$\begin{array}{l}\text { Calculus Index } \\
\text { (CI) }\end{array}$} \\
\hline Baik & 17 & 43.6 & 28 & 36.8 & 45 & 39.1 \\
\hline Sedang & 17 & 43.6 & 38 & 50 & 55 & 47.8 \\
\hline Buruk & 5 & 12.8 & 10 & 13.2 & 15 & 13.1 \\
\hline Rata-rata CI & \multicolumn{2}{|c|}{0.69} & \multicolumn{2}{|c|}{0.78} & \multicolumn{2}{|c|}{0.75} \\
\hline
\end{tabular}

yang terkena maupun daerah sekitar gigi tersebut. Apabila invasi bakteri sudah sampai ke pulpa gigi yang terdiri dari pembuluh darah dan syaraf gigi, maka terjadi infeksi pada pulpa yang akan menyebabkan rasa sakit yang sangat dan berdenyut, sehingga dapat mempengaruhi aktivitas dan fungsi fisiologis serta psikologis pada anak tersebut. Dampak sosial yang dialami anak dengan karies gigi yang tidak terawat antara lain, tidak hadir di sekolah karena sakit gigi. Dampak sosial lain yang mungkin dialami anak terkait dengan kegiatan sekolah adalah kesulitan untuk berkonsentrasi ataupun menyelesaikan tugas karena sakit gigi yang dirasakan. ${ }^{(4,9,12)}$

Karies gigi masih merupakan masalah pada anak sekolah di beberapa kota dan negara di dunia. Salah satunya adalah di daerah bagian barat daya Cina, prevalensi karis gigi yaitu 35\% dengan rata-rata pengalaman karies adalah 1,1, dan 94\% merupakan karies yang tidak terawat. Penelitian di Thailand, dilaporkan bahwa 5,1\% anak usia 12 tahun dan 4,4\%anak usia 15 tahun tidak sekolah karena menderita sakit gigi. Adanya kerusakan gigi secara signifikan memberikan dampak pada kegiatan makan atau memberikan ketidaknyamanan pada saat makan terjadi pada kelom-
Tabel 4. Hubungan Karies Gigi Dengan Kualitas Hidup Anak

\begin{tabular}{lccc}
\hline \multirow{2}{*}{ Variabel } & \multicolumn{3}{c}{ Kualitas hidup } \\
\cline { 2 - 4 } & $\mathbf{n}$ & nilai r & p-value \\
\hline Karies Gigi & 115 & $-0,418$ & $0,000^{*}$ \\
PUFA & & & \\
Karang Gigi & & & \\
Calculus Index (CI) & 115 & $-0,158$ & 0,091 \\
\hline
\end{tabular}

pok umur 12 tahun, sedangkan dampak terhadap aspek psikososial diantaranya adalah terhadap emosi, kegiatan santai dan proses belajar terjadi pada kedua kelompok umur tersebut. Penyakit pada rongga mulut atau kondisi gigi dan mulut yang tidak sehat seperti adanya karies gigi, tidak hanya menyebabkan kerusakan secara fisik pada dental saja namun juga mempengaruhi ekonomi, sosial dan psikologis. Tindakan pencegahan perlu dilakukan secara dini untuk mencapai kualitas hidup anak-anak yang optimal, yaitu dengan mempertahankan gigi asli selama mungkin agar kesehatan gigi dengan fungsi yang optimal dapat dinikmati. (13-16)

\section{Kesimpulan}

Terdapat hubungan yang signifikan antara karies gigi dengan kualitas hidup anak. yang ditunjukkan dengan semakin banyak jumlah gigi yang terkena karies maka skor total COHIP-SF 19 untuk mengukur kualitas hidup anak semakin rendah. Sedangkan untuk karang gigi tidak terdapat hubungan yang bermakna dengan kualitas hidup anak. Hasil penelitian ini dapat menjadi masukan bagi masyarakat untuk meningkatkan kualitas hidup anak untuk lebih memperhatikan status kesehatan gigi dan mulutnya agar tidak mengganggu secara fungsional yang kemudian dapat menurunkan kualitas hidupnya. Bagi pemerintah untuk meningkatkan kualitas hidup anak dengan melakukan upaya-upaya dalam mengatasi masalah yang mengganggu peningkatan kualitas hidup anak termasuk karies gigi dan kebersihan gigi dan mulut.

\section{Ucapan Terima Kasih}

Terima kasih kami ucapkan kepada pemerintah Kabupaten Minahasa Utara khususnya 
di Kecamatan Talawaan yang telah memberikan ijin sebagai tempat penelitian, serta semua pihak yang telah membantu dalam penelitian ini yang tidak bisa disebutkan satu persatu.

\section{Daftar Pustaka}

1. Kemenkes RI. Pedoman Usaha Kesehatan Gigi Sekolah (UKGS). Jakarta: Bina Upaya Kesehatan Kemenkes RI; 2012.

2. Kemenkes RI. Riset Kesehatan Dasar 2013. Jakarta: Badan Penelitian dan Pengembangan Kesehatan; 2013.

3. Depkes RI. Riset Kesehatan Dasar 2007. Jakarta: Badan Penelitian dan Pengembangan Kesehatan; 2007.

4. Krisdapong S, Prasertsom P, Rattanarangsima K, Adulyanon S, Sheiham A. Using associations between oral diseases and oral health-related quality of life in a nationally representative sample to propose oral health goals for 12-year-old children in Thailand. International Dental Journal. 2012;62(2).

5. Kidd EAM, Bechal SJ. Dasar-dasar Karies Penyakit dan Penanggulangannya. II Jakarta: EGC; 1992.

6. Caranza. Clinical Periodontology. Elsevier. 2012:117-8.

7. Monse B, Benzian H, Holmgren C, Palenstein $\mathrm{V}$. PUFA - An index of clinical consequences of untreated dental caries. Community Dentistry and Oral Epidemiology. 2010;17:77-82.

8. Broder H, Wilson-genderson M, Sischo L. Reliability and validity testing for the Child Oral Health Impact Profile-Reduced (COHIP-SF 19). National Institute Of Health.72(4).

9. Gilchrist F, Rodd H, Deery C. Assessment of the quality of measures of child oral health-related quality of life. 2014.

10. Li C, Xia B, Wang Y. Health and Quality of Life Outcomes Translation and psychometric properties of the Chinese (Mandarin) version of the Child Oral Health Impact Profile-Short Form 19 (COHIP-SF 19) for school-age children. 2014;19.

11. Dahlan M. Statistik Untuk Kedokteran dan Kesehatan. Jakarta: Salemba Medika; 2012.

12. Haditono S, Monks F, Knoers A. Psikologi
Perkembangan. Yogyakarta: Gadjah Mada University Press; 2006.

13. Schuurs A, Mooreer W, Prahl-Andersen B. Patologi gigi geligi : kelainan-kelainan jaringan keras gigi. Yogyakarta: Gadjah Mada University Press; 1992.

14. Foo P, Hons B, Sampson W, Roberts R. General Health-Related Quality of Life and Oral Health Impact Among Australians With Cleft Compared With Population Norms ; Age and Gender Differences. The Cleft Palate-Craniofacial Journal. 2012;49:406-13.

15. Zhang S, et al. Dental and periodontal status of 12-year-old Bulang children in China. 2014.

16. Krisdapong S, Prasertsom P, Rattanarangsima K. School absence due to toothache associated with sociodemographic factors, dental caries status, and oral health-related quality of life in 12- and 15-year-old Thai children. 2013:12-14. 